\title{
MEASUREMENTS OF SHALLOW WATER BREAKING WAVE ROLLERS
}

\author{
Merrick C. Haller and Patricio Catalán \\ ${ }^{1}$ Ocean Engineering Program, Department of Civil, Construction and \\ Environmental Engineering, 202 Apperson Hall, Oregon State University, \\ Corvallis, OR. hallerm@engr.orst.edu. \\ ${ }^{2}$ Ocean Engineering Program, catalapa@engr.orst.edu.
}

\begin{abstract}
Large scale laboratory experiments concerning breaking wave propagation over a fixed-bed, barred beach were performed. The primary observations of interest were video intensity time series obtained from a set of high-resolution video cameras in order to study the onset of wave breaking in shallow water and wave roller transformation in the surf zone. The approach is new in the sense that the analysis concentrates on individual breaking waves, as opposed to the more commonly used timeexposure technique, which averages the information over wave group time scales. A new parameter of interest is derived from the video observations based on the instantaneous intensity maximum, which propagates with the roller. The parameter is shown to provide high-resolution information regarding the onset of wave breaking and the spatial evolution of the wave roller. These observations provide a new and quite rigorous test for phaseresolving shallow water wave models.
\end{abstract}

\section{INTRODUCTION}

There have been very few measurements published of individual breaking wave roller geometries in shallow water. A number of investigators have focused on observations of the initial jet-like motion at the onset of breaking before the establishment of the wave roller (e.g. Basco, 1985; Jansen, 1986), while Govender et al. (2002) provide observations of wave roller vertical cross-sections and angles of inclination for a pair of laboratory wave conditions. Yet, presently very little is known about the growth, evolution, and decay of this aerated region of white water as it propagates through the surf zone. On the other hand, it has been pointed out by Madsen et al. (1997) that the roller area and its angle of inclination on the wave front are important quantities 
governing the dissipation rates in breaking waves. Hence, the wave roller also has a primary influence on the balances of mass and momentum in the surf zone (e.g. Svendsen, 1984; Dally and Brown, 1995; Ruessink et al., 2001).

Models for wave roller transformation and dissipation have been given by Svendsen (1984), Deigaard et al. (1991), Stive and Wind (1986), Dally and Brown (1995), and Lippmann et al. (1996); excepting Dally and Brown (1995), all of these models depend on empirical parameterizations of the wave roller geometry. These parameterizations are based on some combination of either the roller vertical cross-sectional area, the fraction of breaking foam on the face of the wave, and/or the water surface slope of the breaking front face. As it turns out, these parameterizations are not well founded on shallow water measurements of wave rollers. Since there is a lack of shallow water roller measurements, investigators have instead used the wave roller data of Duncan (1981). This is a carefully made and nicely detailed data set, but nonetheless it is derived from stationary breakers in deep water (breaking induced by a towed hydrofoil). It is not at all clear that the same wave roller geometric relationships should apply to shallow water breakers.

The present work is focused on analyzing observations of the time and space scales of individual shallow water breaking wave rollers derived from a digital video system. A new analysis technique is described and shown to provide very high-resolution information regarding individual breaking waves. This information provides a rigorous test for models that seek to predict the time and space variability of wave breaking.

\section{EXPERIMENTS}

Large scale laboratory experiments were performed in the Long Wave Flume (LWF) at the O.H. Hinsdale Wave Lab (Oregon State University). The usable length of this flume is approximately $90 \mathrm{~m}$, and it is $3.7 \mathrm{~m}$ wide and $4.6 \mathrm{~m}$ deep. The flume has a flap-type wavemaker at one end with active wave absorption capabilities. The bottom of the flume was configured into a piecewise continuous, barred profile by adjusting the slopes of a series of concrete slabs. The bathymetry is designed to approximate the bar geometry of an observed field beach profile at a 1:3 reduction in scale; specifically, the October 11, 1994 profile of the DUCK94 field experiment (see Scott et al., 2005).

The bottom profile was surveyed with a Total Station and is shown in Figure 1. The LWF coordinate system has the $x$-axis pointing onshore along the centerline with the origin at the wavemaker and the water depth there was maintained at $4.27 \mathrm{~m}$. There is an array of threaded inserts on each wall of the LWF that are spaced at $3.66 \mathrm{~m}$ and designed for instrument mounting. The location of these corresponds to the bay numbers also shown in Figure 1. Six resistance-type wave gages were used to measure free surface elevation and were sampled at $50 \mathrm{~Hz}$. The wave gages were installed on the east wall of the tank at cross shore locations $x=23.45,45.40,52.73,60.04,70.99$ and 84.97 $\mathrm{m}$ (bays19, 13, 11, 9, 6 and 3, respectively). 


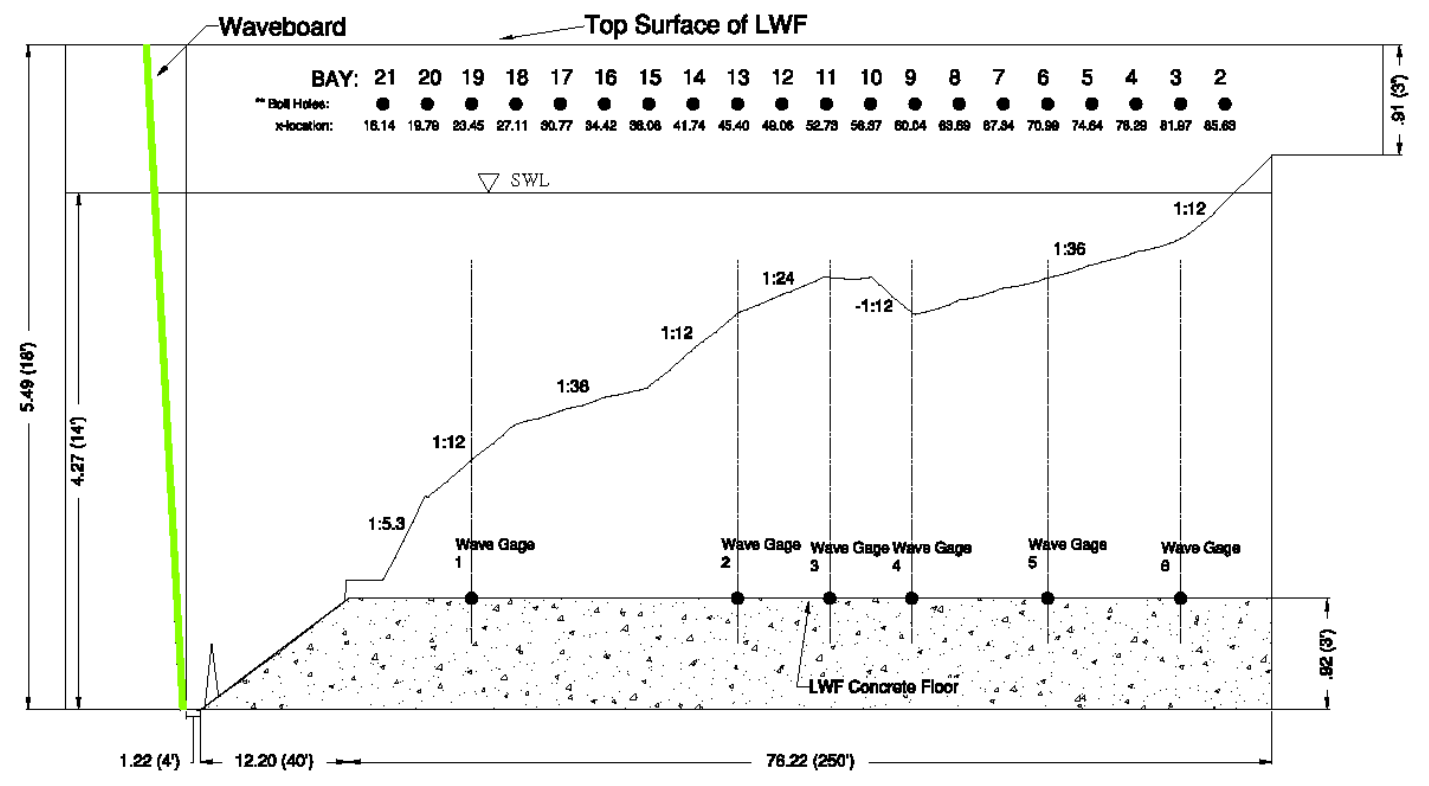

Figure 1: Experimental layout for the Long Wave Flume, including bathymetry, wave gage locations, and bay numbers.

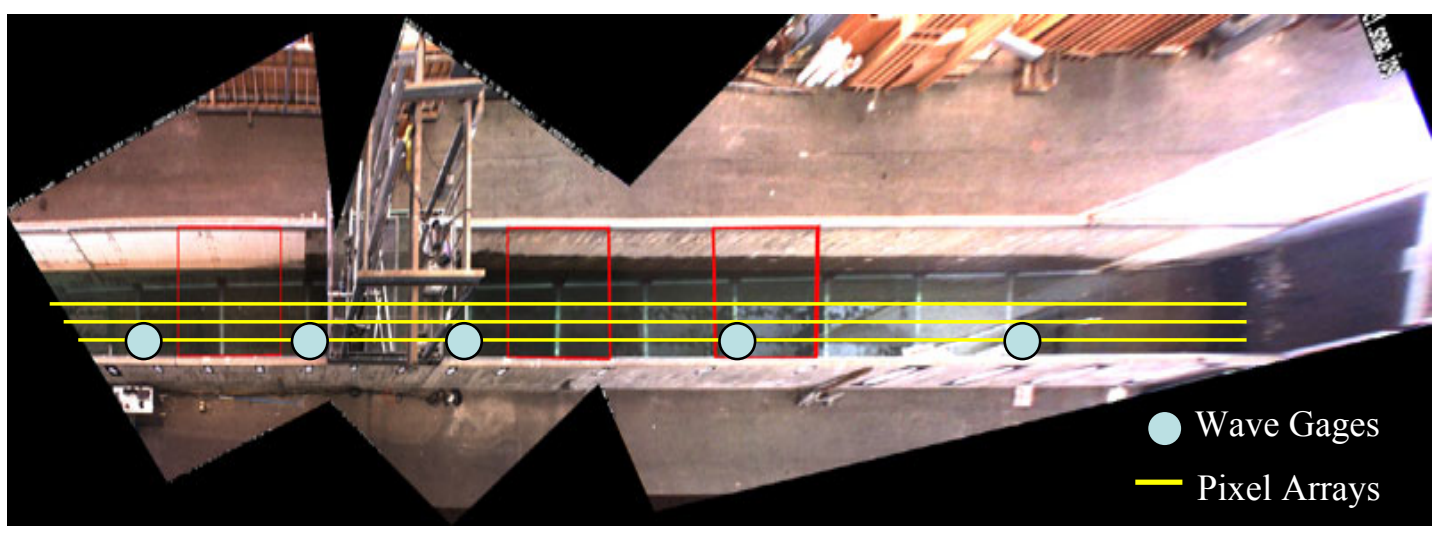

Figure 2: Field of view from the video cameras, pixel arrays shown by yellow lines, wave gages by circles.

Video observations were collected using the new ARGUS III video station installed at the lab. This station is maintained by The Argus Program (Coastal Imaging Lab, COAS, OSU) and consists of three digital cameras mounted near the ceiling and aimed at different sections of the LWF. The field of view of the cameras spans offshore from bay 13 to the dry beach. Individual images (or a series of images) from each camera can be merged and rectified into a single snapshot as shown in Figure 2. Also, shown in the figure are the locations of five of the six in-situ wave gages. The sixth gage is offshore of the field of view. 
Since the LWF covers only a portion of the images, we only sampled three different pixel arrays indicated by the yellow lines in Figure 2. These arrays spanned $41.7<x<$ $100 \mathrm{~m}$ at longshore coordinates $y=-1.2,0$ and $0.6 \mathrm{~m}$ and were sampled at $10 \mathrm{~Hz}$. After interpolation to a uniform grid, there were a total of 5836 pixels in each array with a $\Delta x$ of $1 \mathrm{~cm}$. The wave conditions in the tank were essentially uniform in the $y$-direction (longshore), however, the lighting conditions were not. We restricted our analysis to the pixel array that was least degraded by the ambient lighting conditions.

The total data set consists of 10 separate wave conditions, including 6 regular and 4 random wave conditions. For this work we have only analyzed five of the regular wave conditions, which are listed in Table 1. One regular wave run was neglected due to poor lighting conditions and the random wave tests will be the subject of future work. Further details of the experimental procedure and video data processing can be found in Catalán (2005).

Table 1. Wave Conditions for Regular Wave Tests

\begin{tabular}{c|c|l|c|c|c|c|c}
\hline Run \# & $\mathbf{T}(\mathbf{s e c})$ & $\mathbf{H}_{\mathbf{0}}(\mathbf{m})$ & $\mathbf{H}_{\mathbf{b}}(\mathbf{m})$ & $\mathbf{( k h})_{\mathbf{b}}$ & $\boldsymbol{\xi}_{\mathbf{b}}$ & Breaker type & $\begin{array}{c}\text { \# of } \\
\text { waves }\end{array}$ \\
\hline 40 & 4.0 & 0.59 & 0.56 & 0.43 & 0.28 & spilling & 95 \\
\hline 36 & 4.0 & 0.79 & 0.75 & 0.43 & 0.24 & spilling & 120 \\
\hline 37 & 5.0 & 0.81 & 0.81 & 0.34 & 0.29 & spilling & 92 \\
\hline 38 & 6.0 & 0.66 & 0.70 & 0.28 & 0.37 & $\begin{array}{c}\text { spilling- } \\
\text { plunging }\end{array}$ & 80 \\
\hline 39 & 8.0 & 0.62 & 0.74 & 0.21 & 0.48 & plunging & 60 \\
\hline
\end{tabular}

Values are wave period $(T)$, deep water wave height $\left(\mathrm{H}_{0}\right)$, breaking wave height $\mathrm{H}_{b}$, relative water depth at break point $(\mathrm{kh})_{\mathrm{b}}$, surf similarity parameter defined as

$\xi_{b}=\frac{1}{\sqrt{2 \pi}} \tan \beta\left(\frac{H_{b}}{g T^{2}}\right)^{-1 / 2}$ where $\beta=1 / 24$, and the number of waves in record used for phase-averaging.

\section{RESULTS}

For each of the experimental runs a single pixel array time series is used to generate a time-space map (timestack) of video intensity. An example raw timestack is shown in the top panel of Figure 3. The bright intensity signals derive from the breaking of individual waves, and the diagonal striations represent their propagation in space and time. The local slope of these striations is directly related to the speed of propagation of the breaking (roller) portion of the waves. An analysis of breaking wave phase speeds from this data set can be found in another paper in these proceedings (Catalán and Haller, 2005).

As stated previously, we have only considered the regular wave runs for the present analysis; hence, the periodic nature of the timestacks is clearly evident in Figure 3. It is apparent from the figure that the breaking wave signatures are very repeatable with some shorter time scale variability, as would be expected from the turbulent nature of the breaking wave roller. Since we are interested in the general features of wave rollers, not the intimate details of the turbulence, we phase-average the timestacks in order to 

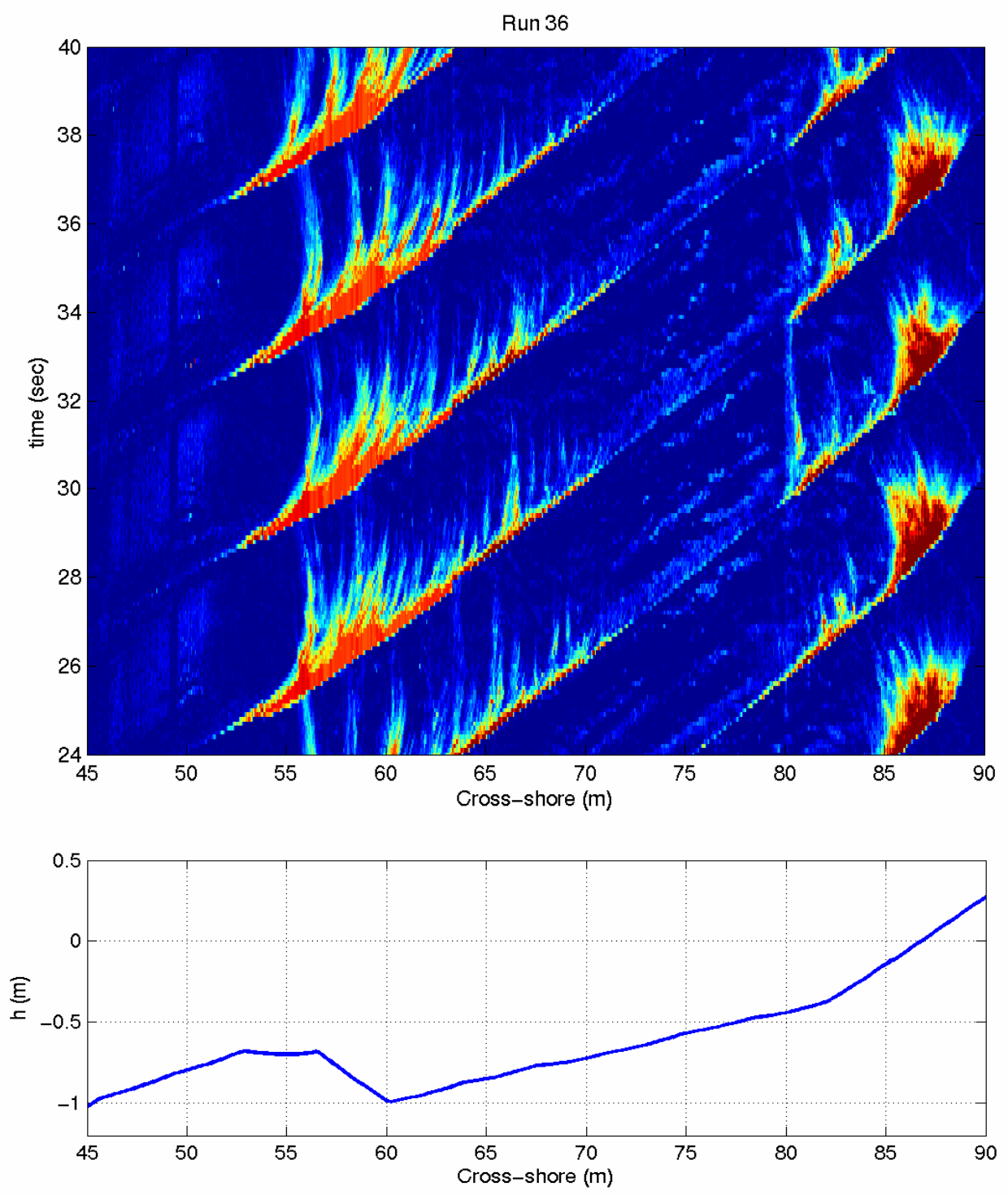

Figure 3: (top panel) Raw time stack of video intensity for Run 36, high intensity events (red colors) represent wave breaking; (bottom panel) partial section of the bathymetry.

remove variability at time scales shorter than a wave period. The phase-averaging involves simply dividing the raw timestack into a number of equal time intervals (approximately the length of the time series divided by the wave period) and averaging along lines of equal phase. We are left with a phase-averaged timestack that spans the same cross-shore distance but only a single wave period in time. Finally, the phaseaveraged stack is smoothed in space by a 31-point running average. Considering the range of observed phase speeds, the effective loss in resolution due to the smoothing is affordable, since the original $\Delta x=1 \mathrm{~cm}$ resolution is highly resolved compared to the $10 \mathrm{~Hz}$ temporal resolution. The smoothing has virtually no effect on the subsequent 

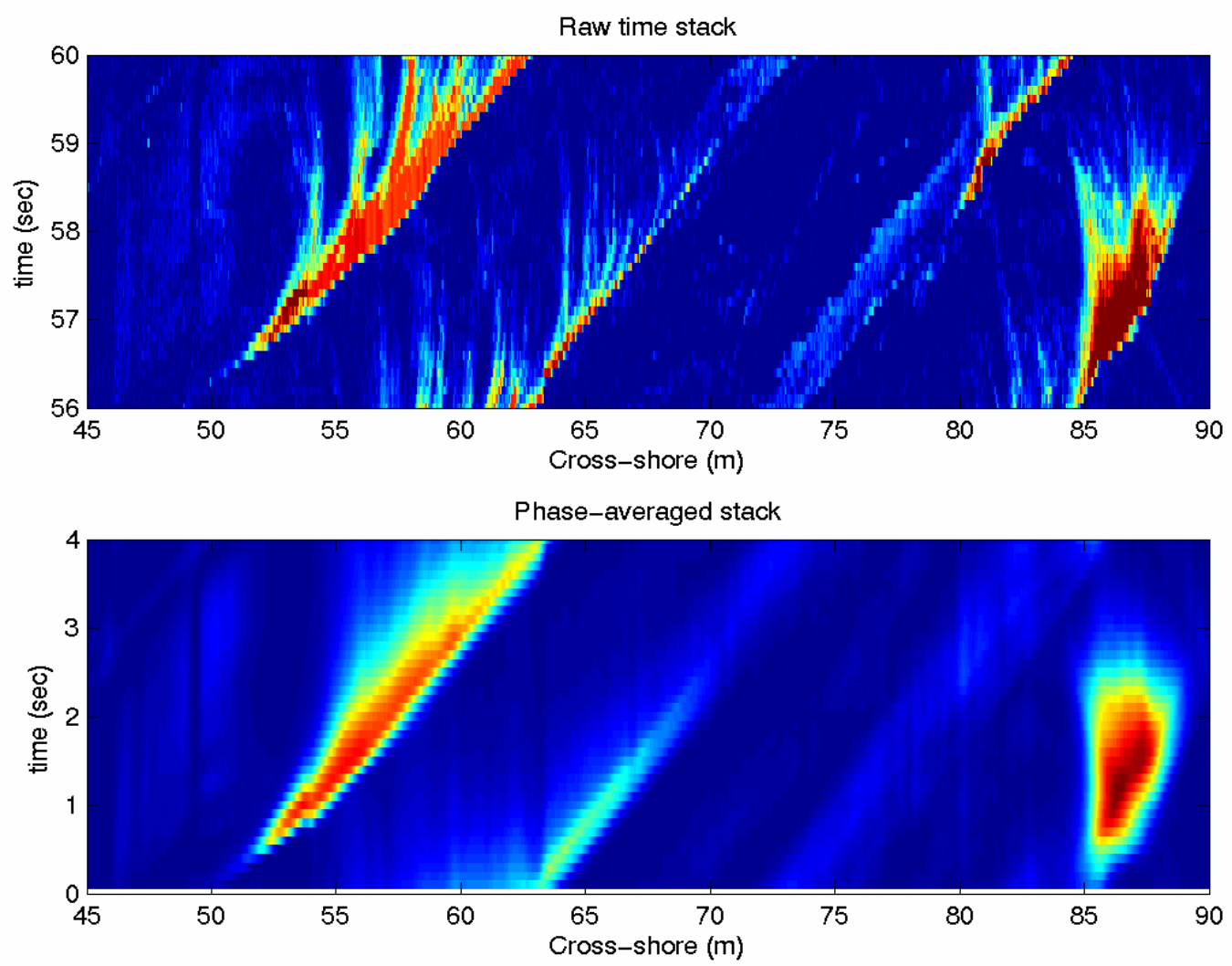

Figure 4: (top panel) Raw time stack of video intensity; (bottom panel) phase-averaged time stack of video intensity, Run 36.

analysis, except to remove some high-frequency jitter in the intensity signal for improved viewing pleasure.

A comparison of one wave realization from a raw timestack and the corresponding phase-averaged version is shown in Figure 4 for the four second wave run. The phaseaveraged timestack is clearly a smoothed version of the raw stack but still shows the main characteristics of the breaking wave. There are, however, slight offsets in the stack near $x=54$ and $64 \mathrm{~m}$, which is the result of a slight error in the geometry used for the camera merge.

Using the phase-averaged timestack we can analyze the transformation of the breaking wave signature as it propagates from the bar to the shoreline. In general, breaking is initiated just offshore of the bar crest, attains a quasi-equilibrium on the shoreward face of the bar, decays through the trough region, and then is re-established near the shoreline. This process can clearly be seen in Figure 5. The figure shows instantaneous cross-shore profiles of phase-averaged intensity, $I\left(x, t^{\prime}\right)$. It is evident that breaking begins near $x=52 \mathrm{~m}$ where the local intensity peak initially takes on a Guassian shape, which increases in amplitude as the wave propagates and the wave roller is fully established. 

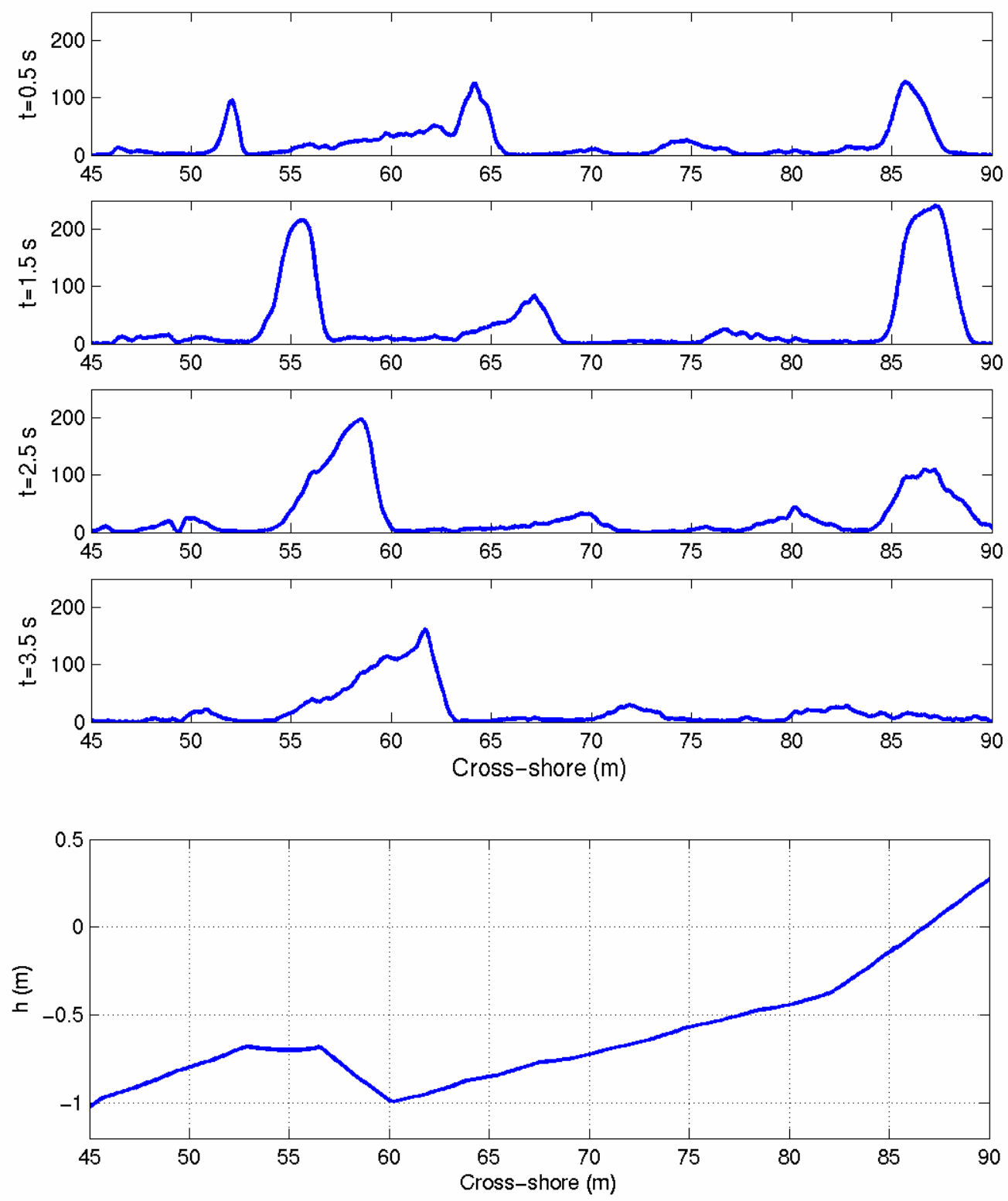

Figure 5. (upper panels) Intensity, $I\left(x, t^{\prime}\right)$ vs cross-shore distance at four different instances in time, each separated by $1.0 \mathrm{sec}$. Wave condition is Run 36. (bottom panel) Partial section of the bathymetry.

Rather quickly, the trailing edge of the roller signal also begins to spread out as the wave passes $x=55 \mathrm{~m}$. This is due to the portion of the turbulence and aerated water that is shed from the trailing edge and left behind. However, the leading edge of the wave roller mostly retains its shape as it propagates. For the cases considered here the leading edge of the roller is also not affected by leftover foam from previous breakers. This is because under these laboratory conditions the leftover foam has a much shorter decay time scale due to the overall shorter bubble lifetimes and decreased foam in fresh water. 

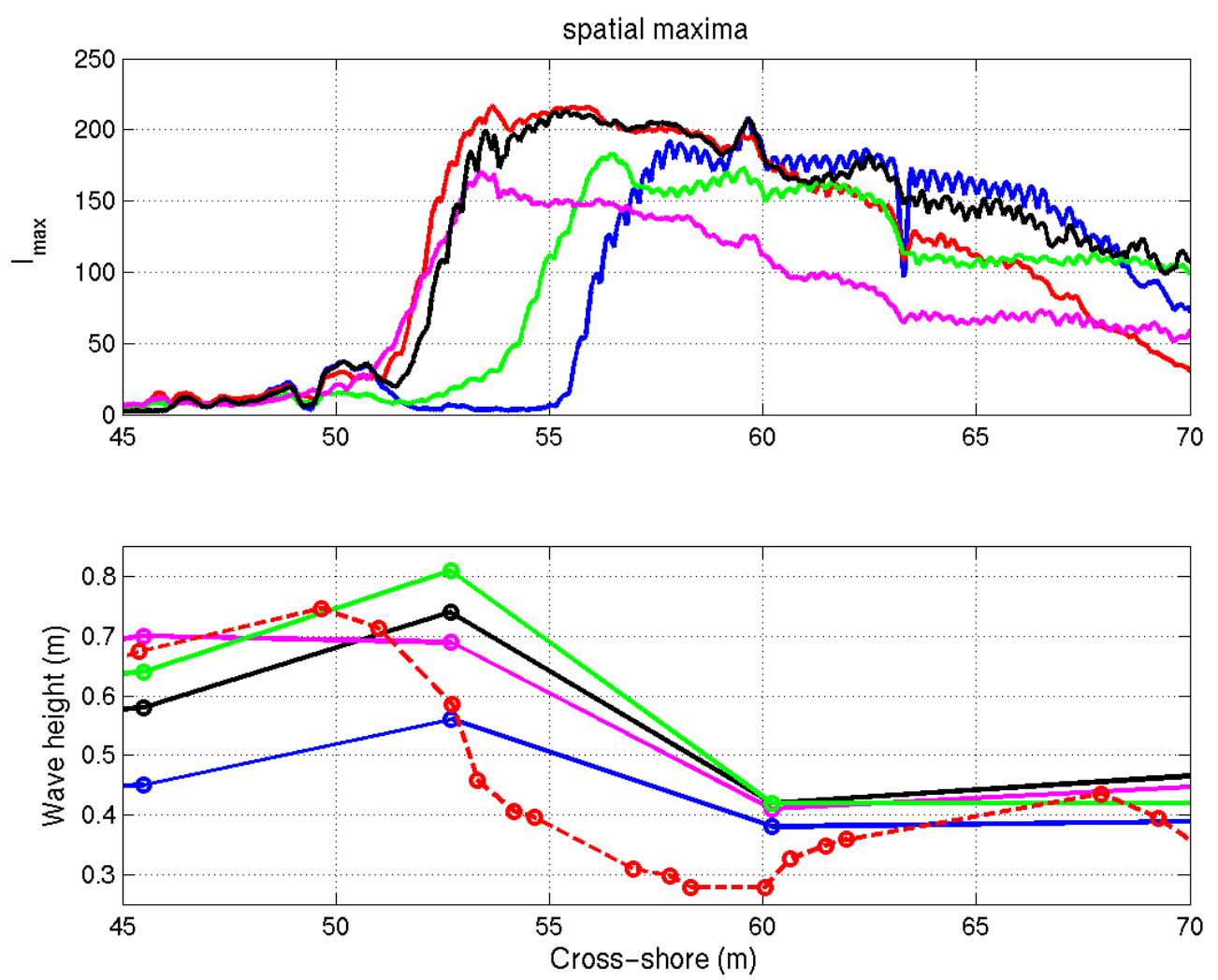

Figure 6. (top panel) $I_{\max }$ vs. cross-shore distance for all runs, (bottom panel) wave heights vs. cross-shore distance; Run 40 (blue), Run 36 (red), Run 37 (green), Run 38 (pink), Run 39 (black).

For the case shown in Figure 5 (Run 36) the intensity peak nearly disappears through the trough as the wave breaking ceases and the wave reforms. But this is not always the case, for the longer waves of Run 39 waves continued breaking through the trough region. Hence, the roller persisted through the trough and the intensity peak can be seen through the trough. The evidence of roller persistence (or lack of it) in the intensity peaks was also confirmed by visual observations made during the experiments. Finally, the data show that all waves then break again as they reach the shoreline. Though analysis of the data in the area very close to the shoreline $(x>85 \mathrm{~m})$ is complicated by the much poorer lighting conditions that existed there and the more persistent foam in the swash zone.

Figure 6 shows the spatial envelopes, or local intensity maxima, $I_{\max }(x)$, for each of the runs. This represents the peak value of intensity over the wave phase, which essentially corresponds to the value when the roller is at that location. The spatial envelopes provide a condensed form of the intensity signals shown in Figure 5 and are a useful quantity for defining the locations of wave breaking and for tracking the evolution of the wave roller. Also shown Figure 6 are the corresponding wave height profiles determined from a zero up-crossing analysis of the wave gage data. Note that for most of the wave 
runs we only had 6 wave gages, four of which were located in the surf zone. However, one of the wave conditions (Run 36) matched that used in the experimental tests of Scott et al. (2005). Their instrumentation also included a mobile wave gage that obtained wave heights at a much higher spatial resolution through a number of repetitive wave runs. In the bottom panel of Figure 6 we have reproduced their data (our fixed gage data for this run is also shown) in order to contrast the different spatial resolutions of the wave data and the very high-resolution information provided by the video data.

The data for Run 36 shown in Figure 6 clearly indicate that the sharp increase in $I_{\max }$ near $x=51 \mathrm{~m}$ directly corresponds to the sharp decrease in the measured wave heights. Hence, $I_{\max }$ provides the location of wave breaking at a very high spatial resolution, effectively of $O(10 \mathrm{~cm})$. Thus, video processed in this manner provides a more efficient, higher resolution method for determining wave breaking locations than is typically feasible with an array of in-situ wave gages. The level of detail is striking when one compares the wave data from other runs with the corresponding video data. We believe the advantage of using the video still holds true when scaling the experiments up to field scale or down to much smaller laboratory work.

The time-exposure is a primary data product from coastal video imaging systems (see e.g. Lippmann and Holman, 1989) and has proven very useful in quantifying nearshore morphology based on the link between wave breaking and the underlying beach profile. It is therefore interesting to compare the information regarding wave breaking contained in $I_{\max }$ with that contained in a time-exposure. In field imaging systems, time-exposures are created by averaging sequences of images over wave group time scales (typically 10 min). For the regular wave cases analyzed herein, averaging the raw intensity signal over any integer number of waves will suffice and we simply average over the total number of waves in a given video record to obtain $I_{b a r}$ (as in overbar).

The parameters $I_{\max }$ and $I_{b a r}$ are compared in Figure 7. The top panel of the figure again shows the cross-shore profiles of $I_{\max }$, although here the profiles contain the full crossshore extent all the way past the still water shoreline. First, it can be seen that for some of the runs the $I_{\max }$ signals persist through the trough, which indicates that the waves continue to break through this region. The middle panel shows the corresponding $I_{b a r}$ profiles. It is quite evident that the time-averaging process reduces the dynamic range of the signal, so much so in fact, that it is very difficult to see in the time-averaged data that wave breaking continues through the trough for some of the runs. In addition, the ramp up of the time-exposure signal and the local maxima over the bar are shifted shoreward from the location where wave breaking initially occurs. This shoreward shift is a well-known effect of the trailing foam and time-exposure analyses usually require extensive efforts to remove this (see Aarninkhof and Ruessink, 2004). So, the comparison suggests that $I_{\max }$ may be a parameter of significant value that is not compromised by the effects of trailing foam, which are not directly related to wave breaking. Thus, $I_{\max }$ can better define where waves are breaking. 

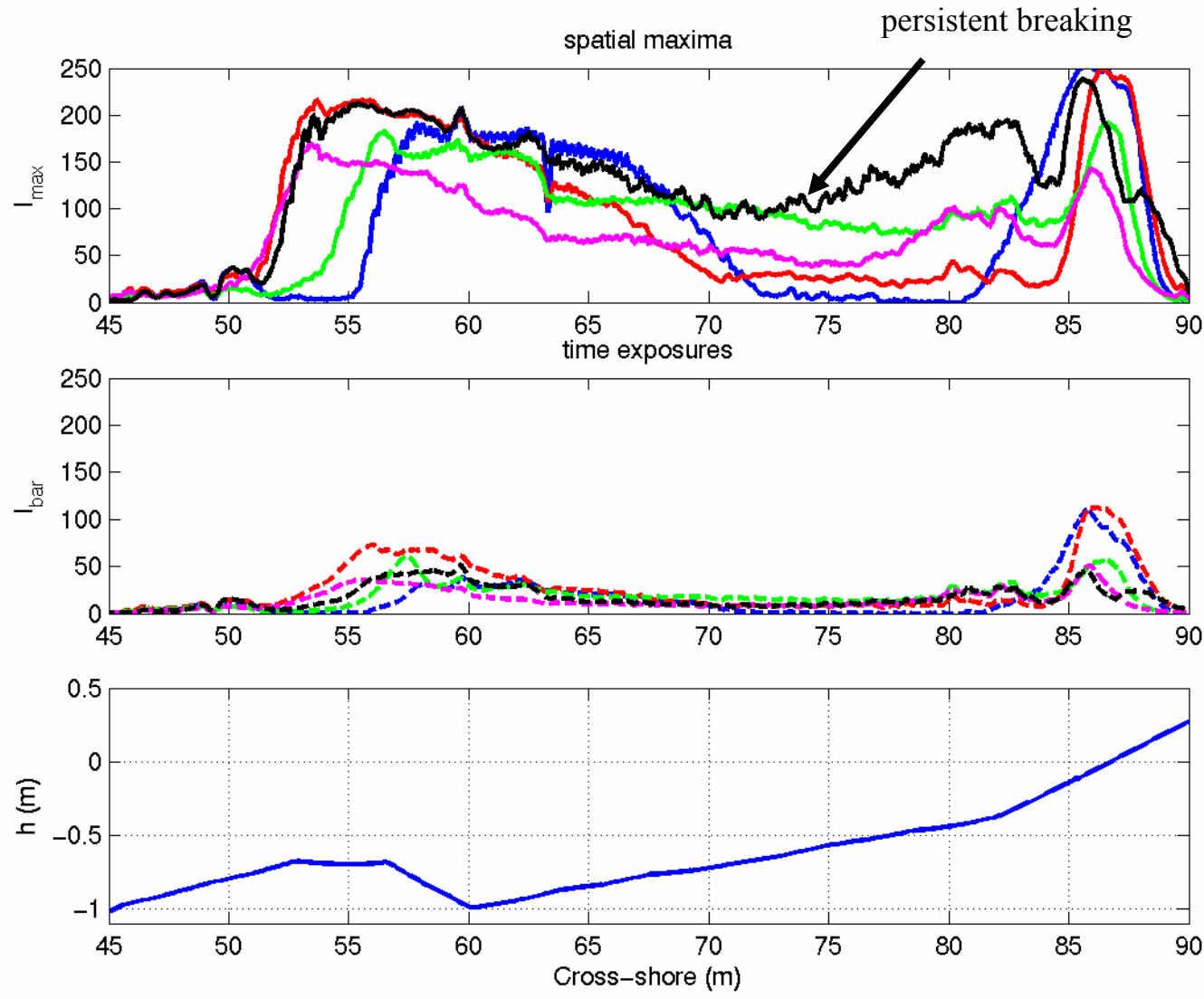

Figure 7. (top panel) $I_{\max }$ vs. cross-shore distance for all runs, (middle panel) $I_{\text {bar }}$ vs. crossshore distance for all runs (bottom panel) partial section of the bathymetry; Run 40 (blue), Run 36 (red), Run 37 (green), Run 38 (pink), Run 39 (black).

Finally, it is of interest to relate physical properties of the wave roller to the underlying wave dissipation that occurs within the roller. Present wave roller dissipation models depend on some combination of either the roller vertical cross-sectional area, the fraction of breaking foam on the face of the wave, and/or the water surface slope of the breaking front face. However, the vertical cross-sectional area is not a property that can be measured in practical circumstances. Ideally, we would be able to relate the wave roller dissipation to physical properties that can be measured remotely.

One length scale that can be measured remotely is the roller width. We define the roller width as the extent of the wave roller in the direction of wave propagation (cross-shore here). This dimension of the roller is also related to the fraction of breaking foam on the front face of the wave. In practice, we define the roller width as the cross-shore distance from the local intensity $(I)$ peak to the shoreward minimum located at the leading edge of the roller. The definition of the peak is straightforward. We define the leading edge minimum as the location where $I$ falls below a background level. This is shown graphically in Figure 8. 
The video data show that as a wave begins to break the roller width ramps up to a maximum value of $O(1 \mathrm{~m})$ and the width then remains fairly constant but the intensity decays through the trough. It is of interest to compare these results to the those of Duncan (1981). The data of Duncan (1981) still stand out as being very detailed and carefully made measurements of breaking wave rollers. However, it is noted that those measurements were made for stationary, deep water breaking waves. We seek to determine if the relationships between the various roller dimensions still apply for the case of depth-induced, shallow water breakers.

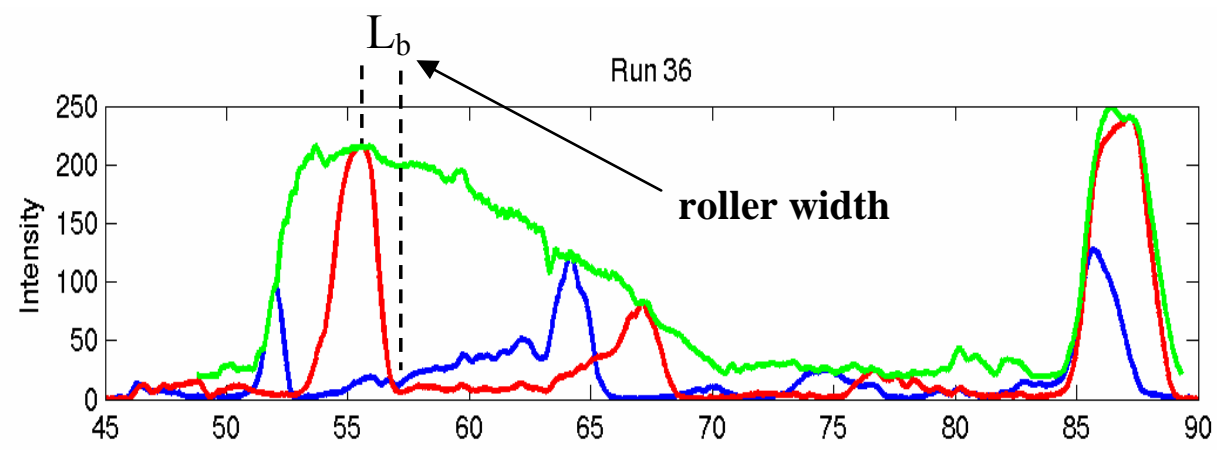

Figure 8. Cross-shore profiles of instantaneous intensity at two separate instances in time (blue) and (red), $I_{\max }$ vs. cross-shore distance (green), all data from Run 36. Instantaneous roller width for a single breaking wave is also shown.

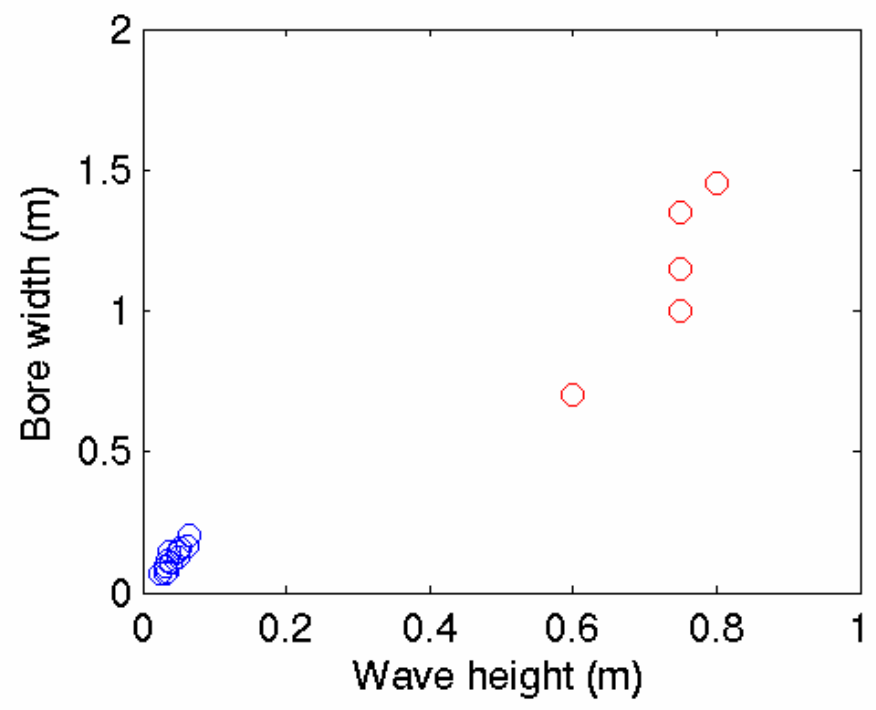

Figure 9. Roller width (or bore width) vs. breaking wave height. Data from Duncan (1981) shown as blue circles, present data as red circles. 
In Figure 9 we have reproduced some of the earlier data. Specifically, we plot the roller width $\left(L_{b}\right)$ versus breaking wave height $\left(H_{b}\right)$. The earlier data imply a linear relationship between $L_{b}$ and $H_{b}$; however, those data cover a limited range and are fairly small scale. We have also plotted the data from our observations, where we have used the maximum bore width observed before the slow decay and the wave height at the break point. Interestingly, the data show a somewhat linear trend with a similar slope to that observed by Duncan. We intend to pursue this issue further.

\section{CONCLUSIONS}

A large scale laboratory data set regarding remote video observations of regular breaking waves was presented. The approach is new in the sense that the analysis concentrates on individual breaking waves, as opposed to the more commonly used time-exposure technique. A new parameter of interest, denoted $I_{\max }$, is introduced based on the instantaneous intensity maximum of the phase-averaged data. The parameter is shown to not be affected by the trailing foam effects that typically hamper timeexposure data. The parameter is also shown to provide high-resolution information regarding the onset of wave breaking and the spatial evolution of the wave roller. In addition, the length scale of breaking wave rollers measured in the direction of wave propagation is analyzed and compared to previous observations of Duncan (1981). The results indicate that there may be a relationship between a remotely measurable wave roller quantity and the underlying wave scales. Finally, it is expected that these observations provide a new and quite rigorous test for phase-resolving shallow water wave models.

\section{ACKNOWLEDGEMENTS}

These experiments would not have been possible without the support of the staff at the O.H. Hinsdale Wave Research Lab, including Tim Maddux, Dan Cox, Chris Scott, and Terry Dibble. In addition, the denizens of the Coastal Imaging Lab made possible the Argus Video Station that was a primary component of the observations. For that we thank Rob Holman, John Stanley, Jason Killian, and Dan Clark.

\section{REFERENCES}

Aarninkhof, S.G.J., and Ruessink, B.G. (2004). "Video Observations and Model Predictions of Depth-Induced Wave Dissipation”, IEEE Trans. Geosci. Remote Sens., Vol. 42, pp.2612-2622.

Basco, D.R. (1985). “A Qualitative Description of Wave Breaking”, J. Waterwy. Por. Coast. Ocean Eng., 111, 171-188.

Catalán Mondaca, P. (2005). "Hybrid Approach to Estimating Nearshore Bathymetry Using Remote Sensing”, M.Oce. Thesis, Dept. of Civil Engineering, Oregon State University.

Dally, W.R., and Brown, C.A. (1995). "A Modeling Investigation of the Breaking

Wave Roller with Application to Cross-shore Currents", J. Geophys. Res., 100(C12), 24,873-24,883.

Deigaard, R., Justesen, P., and Fredsoe, J. (1991). "Modeling of Undertow by a One- 
equation Turbulence Model", Coast. Eng., 15, 431-458.

Duncan, J.H. (1981). "An Experimental Investigation of Breaking Waves Produced by a Towed Hydrofoil”, Proc. R. Soc. Lond., A 377, 331-348.

Govender, K., Mocke, G.P., and Alport, M.J. (2002). "Video-imaged Surf Zone Wave and Roller Structures and Flow Fields", J. Geophys. Res., 107(C7), doi:10.1029/2000JC000755.

Jansen, P.C.M. (1986). "Laboratory Investigations of the kinematics in the aerated region of breaking waves", Coast. Eng., 9, 453- 477.

Lippmann, T.C., and Holman, R.A. (1989). "Quantification of sand bar morphology: A video technique based on wave dissipation”, J. Geophys. Res., 94, 995-1011.

Lippmann, T., Brookins, A.H., and Thornton, E.B., (1996). "Wave energy transformation on natural profiles", Coast. Eng., 27, 1-20.

Madsen, P.A., Schaffer, H.A., and Sorensen, O.R. (1997). "Surf Zone Dynamics Simulated by a Boussinesq-type Model, part 1, Model Description and Crossshore Motion of Regular Waves", Coast. Eng., 32, 255-287.

Ruessink, B.G., Bell, P.S., van Enckevort, I.M.J., and Aarninkhof, S.G.I. (2002). Coast. Eng., 45, 19-32.

Scott, C.P., Cox, D.T., Maddux, T.B., and Long, J.W. (2005). "Large-scale laboratory observations of turbulence on a fixed barred beach", to appear: Measurement Science and Technology: Special Issue on Water Wave Measurements, Institute of Physics Publishing, Inc.

Stive, M.J.F. and Wind, H.G. (1986). "Cross-shore Mean Flow in the Surf Zone", Coast. Eng., 10, 325-340.

Svendsen, I.A. (1984). "Wave Heights and Set-up in a Surf Zone”, Coast. Eng., 8, 303-329. 